\title{
Commentary
}

\section{Challenges Related to Antimalarial Abuse in Coronavirus Disease-2019 Treatment in the Democratic Republic of Congo}

\author{
Anselme Manyong, MPH'*;Ange Landela, MD² \\ 'Chief of Party, Impact Malaria (PMI) DRC Chez Medical Care Development International-MCDI, Kinshasa, Democratic Republic of the Congo \\ ${ }^{2}$ M\&E Officer, PMI Impact Malaria, DRC Technical Diagnostics, Democratic Republic of the Congo
}

\section{${ }^{*}$ Corresponding author}

Anselme Manyong, MPH

Chief of Party, Impact Malaria (PMI) DRC Chez Medical Care Development International-MCDI, Kinshasa, Democratic Republic of the Congo;

E-mail:anselmanyong@yahoo.fr

\section{Article information

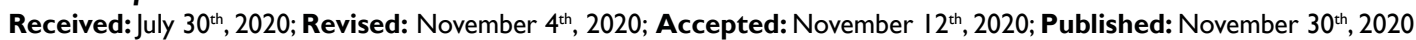

\section{Cite this article}

Manyong A, Landela A. Challenges related to antimalarial abuse in coronavirus disease-2019 treatment in the Democratic Republic of Congo. Epidemiol Open J. 2020; 5(I): 17-18. doi: |0.17|40/EPOJ-5-12|

\section{ABSTRACT}

Malaria is endemic to many African countries and geographies and remains the leading cause of morbidity and mortality on the continent. Ongoing efforts by health authorities to reverse the scale of malaria are often faced to the challenges of drug resistance often generated by therapeutic abuses relating to self-medication, sub-therapeutic under dosages and poor storage and handling of drugs throughout the pharmacy supply chain system.

\section{Keywords}

Malaria; Covid-19; Morbidity and mortality; Abuse antimalarial; Drug resistance.

Since March 10, 2020, when the first case of coronavirus was diagnosed in the Democratic Republic of Congo (DRC) ${ }^{1}$ the country has confronted the harsh reality of the COVID-19 pandemic. As of August 10, 2020 9,484 confirmed cases, and 224 deaths have been reported according to the Ministry of Health's newspaper. ${ }^{1}$ This has resulted in an unadjusted mortality rate of $2.4 \%$.

Malaria is endemic to DRC and remains in most years the leading cause of morbidity and mortality. Ongoing efforts by health authorities to reverse the scale of malaria are often challenged by malarial drug resistance ${ }^{2}$ often caused by factors including self-medication abuses and ineffective or unsafe self-treatment, inadequate, dosages and poor storage and handling of drugs from manufacture to use/administration.

The Coronavirus Disease-2019 (Covid-19) occurrence presents new risks for an already present and worsening problem. Consider the following facts:

- Lack of reliable scientific information on the coronavirus pandemic.
- In the DRC, most of the information on diseases is available in print medias. However, $27.1 \%$ of the population ${ }^{3}$ Demographic and Health Survey, DHS 2004 are illiterate, that means, they cannot read, write or calculate, and therefore cannot access this information.

- Many audio-visual media channels are privately owned and focus then on lucrative activities to support their operations. There is therefore a lack of financial support to identify key prevention messages targeting those who do not have access to written information.

- The extent of rumors, generally false and spread by political tendencies opposed to the government in place, with the aims to accuse them of inefficiency vulgarize in the community false and contradictory information, creating doubt about the real existence of the disease and its spread.

Such confusion thus arouses in people's minds, aggravated by their poverty situation, prevents them from knowing the importance of common barrier measures and practice implementing them. 
- Precarious Social Security Systems.

In the DRC, the vast majority of the population has no social security or support system. Few people have a regular job or receive a salary. The informal sector is the majority: irregular and unstable incomes. It is therefore their ability to pay healthcare that determines access to care frequently leaving those without it relying heavily on family caregivers. The coverage of social security in the formal sector is low, it covers only public employees of few companies. ${ }^{4}$ This poverty leads the population to take refuge in self-medication and therapeutic abuse.

Since the onset of Coronavirus, many therapeutic trials are underway using antimalarial molecules as treatment. Similarly, at the community level, the use of antimalarial drugs, including traditional plants or derivatives is really common without any prior clinical consultation. People limited by economic barriers, do not hesitate to procure in local shops the medicines regardless of any quality nor dosage. This increased familiarity of germs with drugs will make malaria resistance worse.

\section{CONCLUSION}

The precarious context of health systems of developing countries will surely influence the intensification of the spread of COVID-19, because of low awareness of preventive measures among the population. On the other hand, the incorrect or reckless use of anti-malaria molecules in the management of COVID-19 will lead to new resistance to these drugs, with increased rates of morbidity and mortality from malaria. And a greater than ever resulting need for a newer, more expensive but perhaps more durable antimalarial to be developed.

Research on therapeutic efficacy of antimalarial drugs should be undertaken intensively to identify early resistance and address it in time to reduce related mortality and morbidity. Policy makers and financial partners should focus their efforts and attention on establishing a supporting evidence base founded on controlled scientific studies where possible. Also desirable is publication of medical or public health professional society guidance on the sale and use of antimalarial drugs in the management of COVID-19. The government should also rapidly define policy that should cover the population's health needs to reduce and control self-medication. These measures would go further than what is in place today to ensure overall public health and the prevention of future cases of treatment-resistant malaria in the Democratic Republic of Congo.

\section{CONFLICTS OF INTEREST}

The authors declare that they have no conflicts of interest.

\section{REFERENCES}

1. Stop Coronavirus COVID-19 RDC. Web site. https://www. stopcoronavirusrdc.info/. Accessed July 29, 2020.

2. Drug resistance and response. Web site. https://www.who.int/ malaria/areas/drug_resistance/en/. Accessed July 29, 2020.

3. Google Scholar. Web site. https://scholar.google.com/scholar ?q=DRC+Demographic + and + Health + Survey, + DHS $+2004 \& h$ l=en\&as_sdt=0\&as_vis=1\&oi=scholart. Accessed July 29, 2020.

4. Annales Africanies de Medecine. Web site. https://anafrimed. net/quel-systeme-de-securite-sociale-pour-la-rdc-assurance-maladie-mutuelles-assurances-privees/. Accessed July 29, 2020. 